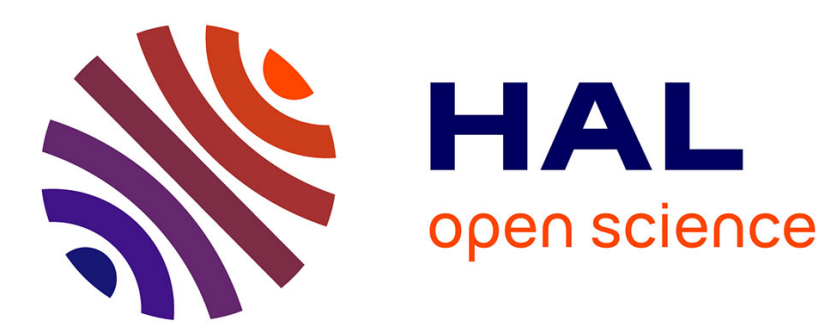

\title{
Cell polarity in Arabidopsis trichomes
}

Daniel Bouyer, V Kirik, M Hülskamp

\section{To cite this version:}

Daniel Bouyer, V Kirik, M Hülskamp. Cell polarity in Arabidopsis trichomes. Seminars in Cell and Developmental Biology, 2001, 12 (5), pp.353 - 356. 10.1006/scdb.2001.0263 . hal-02999223

\section{HAL Id: hal-02999223 \\ https://hal.science/hal-02999223}

Submitted on 14 Dec 2020

HAL is a multi-disciplinary open access archive for the deposit and dissemination of scientific research documents, whether they are published or not. The documents may come from teaching and research institutions in France or abroad, or from public or private research centers.
L'archive ouverte pluridisciplinaire HAL, est destinée au dépôt et à la diffusion de documents scientifiques de niveau recherche, publiés ou non, émanant des établissements d'enseignement et de recherche français ou étrangers, des laboratoires publics ou privés. 


\title{
Cell polarity in Arabidopsis trichomes
}

\author{
D. Bouyer, V. Kirik and M. Hülskamp*
}

\begin{abstract}
Arabidopsis leaf trichomes are unicellular hairs that display a highly characteristic cell form that has a fixed orientation with respect to the basal-distal leaf axis. The genetic, molecular and cell biological analysis of trichome morphogenesis reveal that various cellular processes need to be coordinated including regulation of the cell cycle, the cell size and the actin and tubulin cytoskeleton. Here we will focus on what is known about the establishment and maintenance of positional information during trichome formation.
\end{abstract}

Key words: trichomes / cell division / cytoskeleton / polarity

(c) 2001 Academic Press

\section{Introduction}

How positional information is established and maintained during cell morphogenesis is best understood in cells with a single axis such as budding yeast or the C. elegans, Drosophila or Fucus zygotes. ${ }^{1-3}$ Arabidopsis leaf trichomes have been established as the model system to assess how cell architecture is controlled in cells with a more complex form or multiple axes. ${ }^{4,5}$ During development, the trichome cell proceeds through a series of morphogenetic decisions that reflect changes in its polarity. ${ }^{6}$ Trichomes originate from epidermal cells. The first recognizable change is an increase in nuclear volume due to a switch from mitotic cycles to endoreduplication cycles. Initial cell enlargement is within the plane of the epidermis [Figure 1(a) and (b)]. Then, growth orientation, and thus cell polarity, changes so that the cell grows out of the

From the University of Köln, Botanical Institute III, Gyrhofstrasse 15, 50931 Köln, Germany. *Corresponding author.

E-mail: martin.huelskamp@uni-koeln.de

(C) 2001 Academic Press

$1084-9521 / 01 / 050353+04 / \$ 35.00 / 0$ surface [Figure 1(a) and (b)]. When the cell has undergone two to three endoreduplication cycles, two successive branching events take place. The orientation of both is strongly correlated with respect to the leaf axis [Figure 1(a) and (b)]. The first branching occurs in alignment with the basal-distal leaf axis. At this stage the trichome is asymmetric as the next branching event takes place only on the branch pointing to the leaf tip [Figure $1(\mathrm{a})$ and (b)]. The second branching event is perpendicular with respect to the first one. Further development is characterized by an enormous extension growth resulting in a $500 \mu \mathrm{m}$ long, three-branched cell with a final DNA content of approximately 32C. How the spatial arrangement of morphogenetic events in trichomes is controlled is largely unknown.

\section{Insights from trichome branching mutants}

Extensive mutagenesis screens have identified 15 mutants that affect branching number, although to date no mutants are known that affect the branching pattern. ${ }^{6-9}$ Generally, branching mutants can be grouped in two classes: (1) mutants that have an increased number of branches linked to changes in ploidy level; (2) mutants with altered branch number but a normal DNA content. The analysis of their genetic interactions has shown that most of the genes act in independent pathways, indicating that they participate in different biochemical processes.

Trichome mutants with fewer branches, in particular, shed some light on the regulation of cell polarity of trichomes. The analysis of the relative orientation of the branching plane in the two mutants angustifolia (an) and stachel (sta) revealed a marked difference. While in an-mutants the branching plane is still aligned with respect to the basal-distal leaf axis, sta mutant trichomes are randomly oriented. ${ }^{10}$ This indicates that branching mutants fall into two classes, those in which the spatial orientation with respect to the surrounding tissue is maintained and those in which it is lost. 


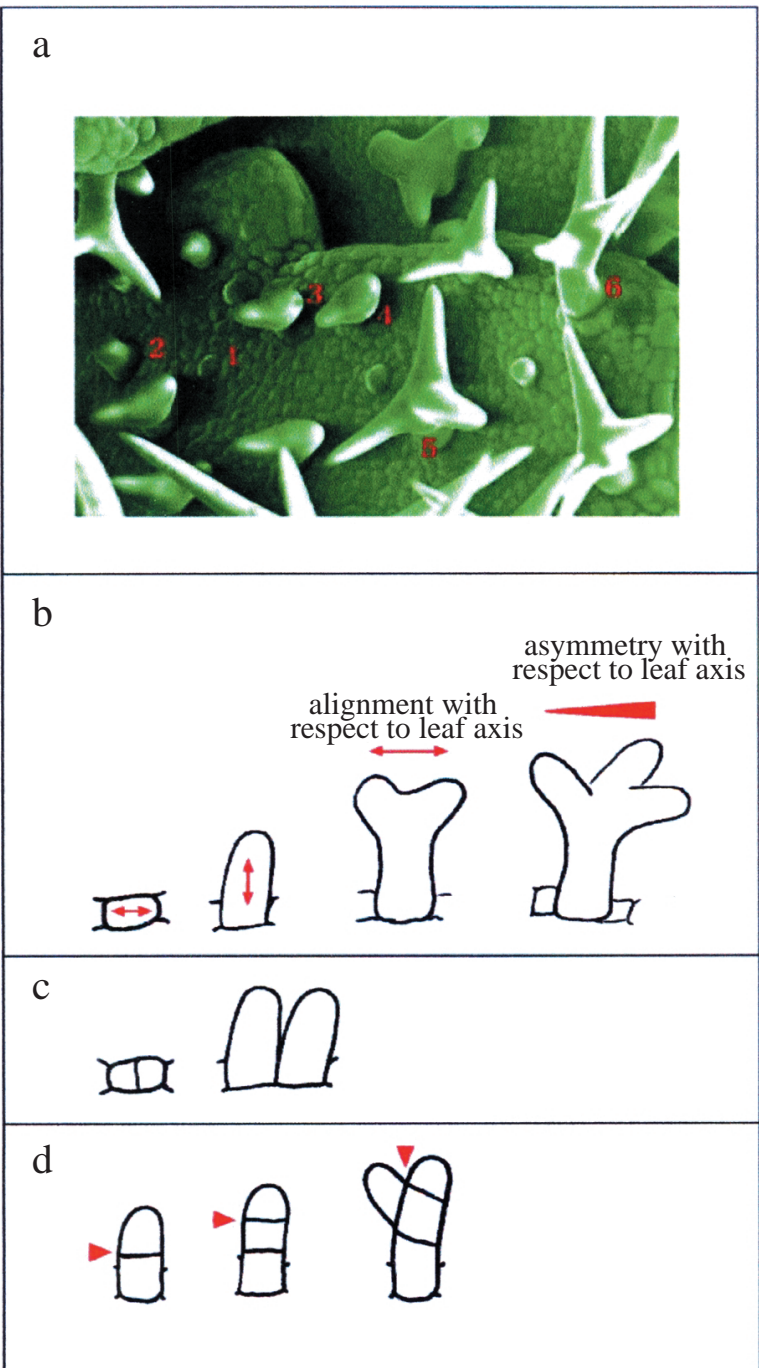

Figure 1. Trichome polarity. (a) Overview of a young leaf with different developmental stages of trichome development. The red numbers depict a series of developmental stages. (b) Schematic presentation of selected developmental stages of trichome development. The red arrows mark the polarity of the trichome cell. (c) Schematic drawing of incipient trichome cells in the sim mutant. Occasionally, an early division takes place before the trichome cell has shifted its polarity resulting in trichome cluster. (d) Schematic drawing of trichome development in Verbascum. Here branching is caused by a change of the cell division plane (marked by red arrow heads).

Similarly to sta mutants, weak stichel (sti)-alleles also have only two branches that are randomly oriented with respect to the leaf axis. STI seems to act as a key regulator of branch initiation. sti mutants exhibit the strongest branching phenotype, strong alleles having unbranched trichomes. ${ }^{6,10}$ In addition $S T I$ acts in a dosage dependent manner; weak sti alleles display intermediate branch numbers, ${ }^{10}$ and increased expression levels in 35S:STI plants result in extra branch formation (Bouyer and Hülskamp, unpublished observations).

The ZWICHEL gene conditions asymmetric growth after the first branching event. With increasing severity of zwi alleles, branch formation and growth is specifically reduced in the distal pointing branch. ${ }^{10}$

In summary, the genetic data indicate that some of the branching gene mutants are not only affected in the actual number of branches but also in their spatial organization, though it is unclear how these quantitative and qualitative effects might be linked.

\section{The microtubule cytoskeleton has a key role in branch formation}

In animals, the microtubule cytoskeleton plays a major role in establishing and maintaining cell polarity. Similarly, in plants microtubules have been demonstrated to be important in the maintenance of the growth axis in tip growing cells such as pollen tubes and root hairs. ${ }^{11}$ However, recent data indicate that the various functions microtubules have in animals, such as the transport of the nucleus, the mobility of mitochondria and the GOLGI, are based on the actin cytoskeleton in plants. ${ }^{12}$ The role of the microtubule and actin cytoskeleton during trichome development has been addressed in drug inhibitor experiments. Treatments with drugs affecting the actin cytoskeleton causes defects late in development during extension growth. ${ }^{13,14}$ By contrast the inhibition of microtubule formation leads to a distortion of trichome polarity. ${ }^{15}$ Trichomes become bloated and branching is reduced or absent. In addition, it has been shown that the drug-mediated stabilization of microtubules is sufficient to trigger branch formation in a sti and zwi mutant background. Thus the microtubule cytoskeleton is also required to induce branching.

Genetic data support this notion. ton/fass mutants that primarily affect the organization of cortical microtubules have also unbranched trichomes. ${ }^{16}$ In addition the cloning of two genes involved in trichome branching, ZWICHEL and AtKTN1, revealed a kinesin-like protein (involved in microtubule based movements of cell components) and a katanin-like protein (involved in the regulation of microtubule stability). ${ }^{17-19}$ 


\section{The multicellular siamese mutant points to a functional link between branching and the regulation of cell divisions}

The recently described siamese (sim) mutant forms trichome clusters and has multicellular trichomes consisting of on average three but up to 15 cells. ${ }^{20}$ Although cell morphogenesis has not been studied in the sim mutant, cell divisions seem to fix changes in cell polarity during trichome development. This is apparent for the formation of trichome clusters that have been shown to consist of clonally related cells in sim mutants. It is conceivable that sim clusters occur when a cell division takes place before the trichome cell has changed its polarity to grow out of the surface [Figure $1(\mathrm{c})$ ]. The mere finding that a single mutation transforms the unicellular Arabidopsis trichome into a multicellular trichome suggests that Arabidopsis trichomes are evolutionarily derived from multicellular forms. In one other species, Verbascum, it has been demonstrated that branching in multicellular trichomes is due to a change in the orientation of cell divisions in otherwise linear cell files [Figure $1(d)$ ] and that the branching pattern reflects a certain division pattern. ${ }^{21}$ It is attractive to speculate that the regulation of branching in the unicellular Arabidopsis trichomes also has its roots in the regulation of cell divisions. In this scenario, the mechanism regulating the spatial orientation of cell divisions is still operating to direct cell growth in the absence of nuclear and cellular division. In this view, quantitative changes in branch number in branching mutants in unicellular trichomes could be explained as a qualitative failure to undergo certain cell divisions in the context of multicellular trichomes. This would imply that some branching genes might be involved in the cell division machinery.

\section{Insights from the cloning of branching genes}

To date four genes have been cloned that are involved in trichome branching. The first branching gene cloned is ZWICHEL. The ZWI gene encodes a kinesin-like calmodulin-binding protein that was independently identified as the calmodulinbinding protein called KCBP. ${ }^{17,18}$ Kinesins are microtubule-based motor molecules involved in intracellular transport processes or the organization of the microtubule organization. At first glance, the function of $Z W I / K C B P$ in trichome branching could either be the directional transport of material to the active growth sites which would be consistent with the finding that $Z W I / K C B P$ functions as a minus-end directed motor. $^{22}$ Alternatively, $Z W I / K C B P$ could be involved in the organization of the microtubules as suggested by the finding that the stabilization of microtubules can compensate for the lack of $Z W I{ }^{15}$ A function of $Z W I / K C B P$ during cell divisions is suggested by two experiments. First, the analysis of the intracellular localization of $Z W I$ in dividing tissue culture cells has shown that $Z W I / K C B P$ is localized to the preprophase band and the phragmoplast thereby clearly marking the polar organization of the dividing cell. ${ }^{23,24}$ Second, microinjection of antibodies interfering with the $\mathrm{Ca}^{2+} /$ calmodulin regulation of $Z W I / K C B P$ causes a metaphase arrest and abnormal cell plate formation in stamen hair cells. $^{24}$

The cloning of the $A N$ gene revealed that it encodes a protein sharing sequence similarities to various proteins including the transcription cofactor CTBP (C-terminal binding proteins) and Brefeldin A ribosilated proteins and contains a PEST motive (known to mediate protein degradation) (Folkers and Hülskamp, unpublished observations). The PEST region shows a consensus sequence similar to mitotic cyclins suggesting that AN protein degradation may be regulated in a cell cycle specific manner. In addition it was found that in an mutants the microtubule-organization is impaired and that AN genetically and molecularly interacts with ZWI. These data suggest that $\mathrm{AN}$ is involved in similar cellular processes to ZWI.

The cloning of the STI gene has shown that it encodes a large protein containing a domain with sequence similarities to eubacterial DNA-polymerase III subunits and that it also contains a PEST sequence (Ilgenfritz and Hülskamp, unpublished observations). These similarities point to a role of STI in DNA replication or cell division related regulation processes.

Mutations in the AtKTN1 gene result in severe defects in various aspects of cell wall biosynthesis such as the fibre length, cell wall thickness and the content of cellulose and hemicellulose. ${ }^{19}$ In addition cell length greatly reduced and trichomes are two-branched. The AtKTN1 gene shows sequence similarity to the microtubule severing protein katanin and, consistent with this observation, the disappearance of perinuclear microtubules in the reorientation of microtubules in elongating cells is disturbed. 


\section{Perspectives}

Recent genetic and molecular data suggest that the establishment of polarity in Arabidopsis trichomes might be based on mechanisms normally controlling cell polarity in the context of cell divisions. These mechanisms are generally very poorly understood, neither the origin of polarity is known nor how polarity leads to morphogenetic changes. Thus, the trichome model system seems to provide an exciting opportunity to study polarity establishment and the role of the cytoskeleton in this context.

\section{References}

1. Doe CQ, Bowerman B (2001) Asymmetric cell division: fly neuroblast meets worm zygote. Curr Opin Cell Biol 13:68-75

2. Quatrano RS (1997) Cortical asymmetries direct the establishment of cell polarity and the plane of cell division in the Fucus embryo. Cold Spring Harb Symp Quant Biol 62:65-70

3. Chant J (1996) Generation of cell polarity in yeast. Curr Opin Cell Biol 8:557-565

4. Hülskamp M, Folkers U, Grini P (1998) Cell morphogenesis in Arabidopsis. BioEssays 20:20-29

5. Oppenheimer D (1998) Genetics of plant cell shape. Curr Opin Plant Biol 1:520-524

6. Hülskamp M, Misera S, Jürgens G (1994) Genetic dissection of trichome cell development in Arabidopsis. Cell 76:555-566

7. Luo D, Oppenheimer DG (1999) Genetic control of trichome branch number in Arabidopsis: the roles of the FURCA loci. Development 126:5547-5557

8. Perazza D et al. (1999) Trichome cell growth in Arabidopsis thaliana can be depressed by mutations in at least five genes. Genetics 152:461-476

9. Krishnakumar S, Oppenheimer DG (1999) Extragenic suppressors of the Arabidopsis zwi-3 mutation identify new genes that function in trichome branch formation and pollen tube growth. Development 126:3079-3088

10. Folkers U, Berger J, Hülskamp M (1997) Cell morphogenesis of trichomes in Arabidopsis: differential regulation of primary and secondary branching by branch initiation regulators and cell size. Development 124:3779-3786

11. Kost BMJ, Chua NH, Mathur J, Chua NH (1999) Cytoskeleton in plant development. Curr Opin Plant Biol 2:462-470

12. Hawes CR, Satiat-Jeunemaitre B (2001) Trekking along the Cytoskeleton. Plant Physiol 125:119-122

13. Mathur J, Spielhofer P, Kost B, Chua N-H (1999) The actin cytoskeleton is required to elaborate and maintain spatial patterning during trichome cell morphogenesis in Arabidopsis thaliana. Development 126:5559-5568

14. Szymanski DB, Marks MD, Wick SM (1999) Organized Factin is essential for normal trichome morphogenesis in Arabidopsis. Plant Cell 11:2331-2648

15. Mathur J, Chua NH (2000) Microtubule stabilization leads to growth reorientation in Arabidopsis thaliana trichomes. Plant Cell 12:465-477

16. Torres-Ruiz RA, Jürgens G (1994) Mutations in the FASS gene uncouple pattern formation and morphogenesis in Arabidopsis development. Development 120:2967-2978

17. Oppenheimer DG et al. (1997) Essential role of a kinesinlike protein in Arabidopsis trichome morphogenesis. Proc Natl Acad Sci USA 94:6261-6266

18. Reddy ASN, Safadi F, Narasimhulu SB, Golovkin M, $\mathrm{Hu}$ X (1996) A novel plant calmodulin-binding protein with a kinesin heavy chain motor domain. J Biol Chem 271:7052-7060

19. Burk DH, Liu B, Zhong R (2001) A katanin-like protein regulates normal cell wall biosynthesis and cell elongation. Plant Cell 13:807-828

20. Walker JD, Oppenheimer DG, Concienne J, Larkin JC (2000) SIAMESE, a gene controlling the endoreduplication cell cycle in Arabidopsis thaliana trichomes. Development 127:3931-3940

21. Uphof JCT (1962) Plant Hairs, pp. 1-206. Gebr. Bornträger, Berlin

22. Song H, Golovkin M, Reddy ASN, Endow SA (1997) In vitro motility of AtKCBP, a calmodulin-binding kinesin protein of Arabidopsis. Proc Natl Acad Sci USA 94:322-327

23. Bowser J, Reddy ASN (1997) Localization of a kinesin-like calmodulin-binding protein in dividing cells of Arabidopsis and tobacco. Plant J 12:1429-1437

24. Vos JW, Safadi F, Reddy AS, Hepler PK (2000) The kinesinlike calmodulin binding protein is differentially involved in cell division. Plant Cell 12:979-990 